\title{
Teaching Mathematics through Concept Motivation and Action Learning
}

\author{
Sergei Abramovich $\mathbb{D D}^{1}$ Arcadii Z. Grinshpan $\mathbb{D}^{2},{ }^{2}$ and David L. Milligan $\mathbb{1 D}^{2}$ \\ ${ }^{1}$ State University of New York at Potsdam, Potsdam, NY, USA \\ ${ }^{2}$ University of South Florida, Tampa, FL, USA \\ Correspondence should be addressed to Sergei Abramovich; abramovs@potsdam.edu
}

Received 17 August 2018; Revised 27 February 2019; Accepted 13 March 2019; Published 14 April 2019

Academic Editor: Eddie Denessen

Copyright (c) 2019 Sergei Abramovich et al. This is an open access article distributed under the Creative Commons Attribution License, which permits unrestricted use, distribution, and reproduction in any medium, provided the original work is properly cited.

\begin{abstract}
This is a practice-led, conceptual paper describing selected means for action learning and concept motivation at all levels of mathematics education. It details the approach used by the authors to devise insights for practitioners of mathematics teaching. The paper shows that this approach in mathematics education based on action learning in conjunction with the natural motivation stemming from common sense is effective. Also, stimulating questions, computer analysis (internet search included), and classical famous problems are important motivating tools in mathematics, which are particularly beneficial in the framework of action learning. The authors argue that the entire K-20 mathematics curriculum under a single umbrella is practicable when techniques of concept motivation and action learning are in place throughout that broad spectrum. This argument is supported by various examples that could be helpful in practice of school teachers and university instructors. The authors found pragmatic cause for action learning within mathematics education at virtually any point in student academic lives.
\end{abstract}

\section{Introduction}

Nowadays, students require both cognitive and practical experiences throughout the continua of their mathematics education to be productive 21 st century citizens. The genesis of this statement can be traced back to the writings of John Dewey, who emphasized the importance of educational activities that include "the development of artistic capacity of any kind, of special scientific ability, of effective citizenship, as well as professional and business occupations" ([1], p. 307). More recently, Billett [2], based on his studies of integrating learning experiences of tertiary students in the disciplines related to nursing and like services in support of human needs, suggested that "it might be possible to fully integrate practice-based experiences within the totality of higher education experiences that are generative of developing robust and critical occupational knowledge" (p. 840). The main argument of the present paper is that in the context of mathematics education, action learning (the concept introduced in Section 3) is the very process to impart these experiences in conjunction with concept motivation (a term introduced in Section 2) when teaching mathematics across the entire K-20 curriculum. To this end, this practice-led, conceptual paper, detailing the approach used by the authors to devise insights for practitioners of mathematics teaching, offers a survey of selected means for action learning across the formal mathematics education continuum. To a certain extent, this paper promotes the idea of learning through practice [3] in the context of mathematics education. Arguments supporting the value of action learning for all individuals involved (at the college level, adding to the duo of student and mathematics instructor a third community or university nonmathematics professional) are presented (Sections 2-4). Also considered is integration of computer-assisted signature pedagogy (CASP) and nondigital technology as well as effective questioning with action learning (Sections 5 and 6).

Students may joyfully experience formal mathematics education for twenty years or more, and they can be motivated everywhere across the expansive mathematics 
curricula. Action learning in mathematics education combined with rote theory brings mathematical topics to the real world. Naturally, primary-level instances are of foundational importance, and this is reinforced with secondary-level action learning (Sections 4.1 .1 and 4.1.2). The open problems of mathematics can often be introduced to students in primary, secondary, and tertiary education (Section 7). Traditionally, classic results and open problems serve to motivate not only the students but also the educators themselves. Since effective mathematics teachers are needed, action learning should be used promotionally at all levels of mathematics education, knowing that future instructors are amongst the current student population. Certainly, the possibility of being involved in discovery is highly motivational to all, including students and mathematics teachers, at least.

\section{Curiosity and Motivation}

Though the necessity of mathematical learning at the primary, secondary, and tertiary schools is common knowledge, the question on how to teach mathematics is controversial. As described in more detail in [4], with references to [5-10], the controversy is due to a nonhomogeneity of teacher preparation programs, the formalism versus meaning disagreement among mathematics faculty, and various perspectives on the use of technology. We believe that an appropriate way to teach mathematics at all levels is to do it through applications rather than to use traditional lectures, emphasizing the formalism of mathematical machinery. Real-life applications keep concerned people motivated while learning mathematics. This natural motivation can be considered as an agedependable process spanning from natural childhood curiosity in the primary school to true intellectual curiosity at the tertiary level. Regardless of the age of learners, one can see curiosity as motivation "to acquire or transform information under circumstances that offer no immediate adaptive value for such activity" ([11], p. 76). That is, curiosity and motivation are closely related psychological traits.

Most of the studies on the development of curiosity deal with the primary education. However, these studies can inform our understanding of how curiosity turns into a motivation to become high-quality professional. For example, Vidler [12] distinguished between epistemic and perceptual curiosity, which are manifested, respectively, by "enquiry about knowledge and is shown, for example, when a child puzzles over some science problem he has come across ... [and] increased attention given to objects in the child's immediate environment as, for example, when a child stares longer at an asymmetrical rather than a symmetrical figure on a screen" (p. 18). Likewise, adult learners at the tertiary level can become motivated by their mathematics instructor's call for questions concerning information that was shared or by their experiences with the world around them as they try to interpret "the fabric of the world ... [using] some reason of maximum and minimum" (Euler, cited in [13], p. 121).
Related to the tertiary level, Vidler [14] defined achievement motivation as "a pattern of ... actions ... connected with striving to achieve some internalized standard of excellence" (p. 67). There are also adult learners who "are interested in excellence for its own sake rather than for the rewards it brings" ([14], p. 69). Biggs [15] admits that intrinsic motivation in the study of mathematics is associated with "the intellectual pleasure of problem solving independently of any rewards that might be involved ... [suggesting that] the aims of deep learning and of achievement motivation ultimately diverge" (p. 62). A classic example in support of this suggestion is a solution of the (century old) Poincare conjecture by geometer Grigory Perelman who, after almost a decade of "deep learning," declined several international awards for his work including the Fields Medal (the mathematician's "Nobel Prize”) and (\$1 million) Clay Millennium Prize (https://www.claymath. $\operatorname{org} /)$.

As curiosity is the genesis of motivation to learn, Mandelbrot [16], in a plenary lecture on experimental geometry and fractals at the 7th International Congress on Mathematical Education, advised the audience of mostly precollege mathematical educators of how to pivot on $\mathrm{cu}-$ riosity when teaching mathematics: "Motivate the students by that which is fascinating, and hope that the resulting enthusiasm will create sufficient momentum to move them through that which is no fun but is necessary" (p. 86). It is this kind of motivation that the authors describe as concept motivation. More specifically, in this paper, the term concept motivation means a teaching strategy through which, using curiosity of students as a pivot, the introduction of a new concept is justified by using it as a tool in applications to solving real problems. For example, the operation of addition can be motivated by the need to record the augmentation of a large quantity of objects by another such quantity, the concept of irrational number can be motivated by the need to measure perimeters of polygonal enclosures on the lattice plane (called the geoboard at the primary level), or the concept of integral can be motivated by the need to find areas of curvilinear plane figures.

Another mathematically relevant instrument of motivation is concreteness. According to David Hilbert, mathematics begins with posing problems in the context of concrete activities "suggested by the world of external phenomena" ([17], p. 440). We believe that "concreteness" is an appropriate synonym for motivation as it relates to mathematics education. The term concrete itself indicates that a variety of ingredients are brought together and synthesized. The goal of learning mathematics is to concretize notions, both theoretical and applied. It is helpful to have a precise understanding of something. Humans inherently wish to have "full" knowledge of certain things. By knowing details, and concretizing ideas, we reduce anxiety associated with describing and using those ideas. Concreteness motivates all parties involved in mathematics education. Even at the administrative level, there is understanding that "the FKL [Foundations of Knowledge and Learning] Core Curriculum will provide you with the opportunity to explore a variety of vital areas of study, making 
you more aware and engaged in understanding the challenges that our global realities require" ([18], italics added), where the "realities" is given our emphasis. This is motivation for everybody, since we would all like to make use of mathematical theory or, at least, see it applied. Consequently, motivation is proportionally higher for adult learners over children who may not see "usefulness" in mathematics. At the University of South Florida, instructors of certain courses (the calculus sequence, for example) are asked to include the FKL statement in their syllabi.

Until recently, the terms "industrial" and "technical" had rather pejorative connotations in mathematics education. Traditional formal lecturing is still dominant in most classrooms. However, there is often some "industry" or "technique" in examining mathematical theory, so these two notions are not complimentary. It is hard to identify a part of the massive volume of K-20 mathematics curricula which precludes either theory or eventual real-world application. Furthermore, theory is implicitly included in STEM education due to its science component.

In the context of mathematics teacher education, a focus on applications gives future teachers one very important ability of exemplifying mathematical ideas in ways which are usable. This ability can then be imparted to their own students. One can recognize at the precollege level that mathematics knowledge stems from the need to resolve reallife situations of different degrees of complexity. The curriculum principle put forth by the National Council of Teachers of Mathematics [19] includes the notion that all students at this level should be offered experiences "to see that mathematics has powerful uses in modeling and predicting real-world phenomena" (pp. 15-16). This emphasis on applications goes beyond the precollege level. Indeed, mathematics has been greatly developing and penetrating all the spheres of life, making collegiate mathematics education a necessary yet controversial element of the modern culture.

\section{Action Learning}

Many people are pragmatic by doing what works. When something does not work, one is compelled to ask questions as to how to make it work. Beginning from the 1940s, Reginald Revans started developing the action learning concept, a problem-solving method characterized by taking an action and reflecting on the results, as an educational pedagogy for business development and problem-solving $[20,21]$. Since that time, action learning has come to describe a variety of forms it can take and contexts it can be observed. In the context of achieving high quality of university teaching, "the target of action learning is the teaching of the individual teacher" ([22], p. 7). In the general context of improving professional performance, Dilworth [23] argues that action learning starts with an inquiry into a real problem so that regardless whether the problem is "tactical or strategic... [the process of] learning is strategic" (p. 36). Action learning in mathematics education can be defined as learning through student individual work on a real problem followed by reflection on this work. In most cases, this work is supported by a "more knowledgeable other."
In mathematics education, action learning, the genesis of which is in the early childhood experience, has natural levels of maturity. Before we become concerned with the day-to-day responsibilities attached to adulthood, we can freely consider action learning in a game form. Our fondness for gaming and for learning winning strategies are carried into later life, both as means of entertainment and as a tool for instructing the next generation of children. The motivation for action learning in mathematics education gradually changes from winning games to success in real-world ventures. The key to success is the ability to solve problems. Research finds that curiosity can be characterized in terms of excitement about peculiar observations and unexpected phenomena [24]. Additionally, "What children will be curious about depends in large part on the nature of the world about them and their previous experience" ([12], p. 33). Students at all educational levels seek concreteness, are naturally curious about the real world, and enjoy benefits of action learning, especially when they use it repeatedly in mathematics education. In particular, in the postsecondary mathematics curriculum for nonmathematics majors, the problems should have applicability to reality. Interestingly, we seem to return to "gaming" when we deal with pure theory, since we might seek an abstract solution for the sake of solution itself.

Max Wertheimer, one of the founders of Gestalt psychology, argued that for many children, "it makes a big difference whether or not there is some real sense in putting the problem at all" ([25], p. 273). He gave an example of a 9year-old girl who was not successful in her studies at school. In particular, she was unable to solve simple problems requiring the use of basic arithmetic. However, when given a problem which grew out of a concrete situation with which she was familiar and the solution of which "was required by the situation, she encountered no unusual difficulty, frequently showing excellent sense" ([25], pp. 273-274). Put another way, the best strategy to develop students' interest in a subject matter is to focus teaching on topics that are within their basin of attraction. As William James, a classic of American psychology, who was the first to apply it to the education of teachers, put it, "Any object not interesting in itself may become interesting through becoming associated with an object in which an interest already exists" ([26], p. 62). Interest can be also used to develop motivation in education as it "refers to pattern of choice among alternatives-patterns that demonstrate some stability over time and that do not appear to result from external pressures" ([27], p. 132).

Reflection is as important as action. Being able to reflect on action carried out constitutes the so-called internal control when individuals think of themselves as being responsible for their own behavior, something that is different from external control when seeing others or circumstances being the primary motivation for an individual behavior [28]. Three basic questions commonly begin the action learning process in addressing a real problem. We ask: First, what should be happening? Second, what is stopping us from doing it? Third, what can we do? 
Action learning (often referred to in academia as action research $[29,30]$ ) has been traditionally used for teaching business management and the social sciences [31, 32], conducting scientific research [33], and teacher development [22, 34-36]. In mathematics education [4, 37], action learning, as a teaching method, has been adopted as pedagogy oriented on self-solving real problems followed up by reflection. Learning is the primary goal, even though the problem-solving is real and important. Learning is facilitated by breaking out well-established mind-sets, thereby presenting a somewhat unfamiliar setting for the problem. We now have the technology-assisted, action learning pedagogy for teaching mathematics through real-world problems, guided by STEM instructors and community professionals, employing a project component [4]. Digital technology is seen at least within the requisite typology of the manuscripts. It may go much further, of course, and include an essential utility (e.g., a numerical integrator, a spreadsheet, or specialized software). Finally, action learning (with origins in business education $[20,21]$ ) provides an effective and clear approach to mathematics education. This approach was developed out of different (and, as mentioned at the beginning of Section 2, sometimes controversial) active learning techniques which are ubiquitous among mathematics educators across a variety of constructivist-oriented, student-centered teaching contexts [38-41].

\section{Action Learning in the Practice of Mathematics Education}

Our USF-SUNY team [4] has established that action learning is a positive pedagogical feature throughout all grade levels (K-20). One may argue that since many people are lifelong learners, some of us may employ action learning (perhaps as mathematics instructors) beyond K-20. Our motivation to action learning mathematics can give young students a taste of the interesting things known of mathematics. The underlying concepts can be quite sophisticated and students may return to the ideas and take them further as they gather experience. Examples of action learning are presented in the subsections below by instruction level. These examples are given with an emphasis on the goal of concreteness, which in turn motivates the learners. Employing a project component makes the "one + two" Mathematics Umbrella model available at the tertiary level (Section 4.2.2).

4.1. Motivation and Action Learning at the Primary and Secondary Levels. At the primary school level, mathematical concepts can be motivated through the appropriately designed hands-on activities supported by manipulative materials. Such activities have to integrate rich mathematical ideas with familiar physical tools. As was mentioned above, an important aspect of action learning is its orientation towards gaming. A pedagogical characteristic of a game in the context of tool-supported mathematics learning is one's "thinking outside the box," something that in the presence of a teacher as a "more knowledgeable other" opens a window to students future learning. Nonetheless, the absence of support can be observed, as Vidler [12] put it, "when a child stares longer at an asymmetrical rather than a symmetrical figure" (p. 18) recognizing intuitively, through perceptual curiosity, that stability of a figure depends on its position. That is, perceptual curiosity combined with creative thinking often transcends activities designed for one level and merges into the study of more advanced ideas at a higher cognitive level. The following two sections demonstrate how the use of two-sided counters and square tiles, physical tools commonly used nowadays in the elementary mathematics classroom, can support, respectively, the introduction of Fibonacci numbers, allowing one through the use of computing to open a window to the concept of the Golden Ratio, and to connect the construction of rectangles (out of the tiles) to the discussion of special numeric relationships between their perimeters and areas. In both cases, the transition from the primary level to the secondary one can be facilitated by the use of digital technology. That is, mathematical ideas, born in the context of action learning with physical tools, can be extended to a higher level through computational experiments supported by digital tools.

4.1.1. From Two-Sided Counters to the Golden Ratio through Action Learning. Consider the following action learning scenario:

Determine the number of different arrangements of one, two, three, four, and so on two-sided (red/yellow) counters in which no two red counters appear consecutively.

Experimentally, one can conclude that a single counter can be arranged in two ways, two counters in three ways, three counters in five ways, and four counters in eight ways (Figure 1). In particular, Figure 1 shows that all the arrangements with four counters can be counted through recursive addition $3+5=8$ as they can be put in two groups so that in the first group (with cardinality three), the far-right counter is red, and in the second group (with cardinality five), the far-right counter is yellow. By putting this idea into action under the guidance of a teacher, a young student can discover that the next iteration (five counters-13 ways, as $13=5+8$ ) agrees with the description of Figure 1. Augmenting, for consistency, the sequence $2,3,5,8,13$ by two ones (assuming that an empty set of counters has only one arrangement) allows one to describe the completion of the above action learning scenario (that is, reflecting on the results of acting on concrete materials according to a certain rule) through the sequence $1,1,2,3,4,5,8,13, \ldots$, (in which the first two numbers are equal to one and every number beginning from the third is the sum of the previous two numbers)-one of the most celebrated number sequences in the entire mathematics named after Fibonacci (1270-1350), the most prominent Italian mathematician of his time. As part of reflection on the scenario, young students can be told that as esoteric as Fibonacci numbers might seem, they are likely to encounter them again.

Indeed, at the secondary level, Fibonacci numbers $F_{n}$ can be explored in terms of the ratios of two consecutive 


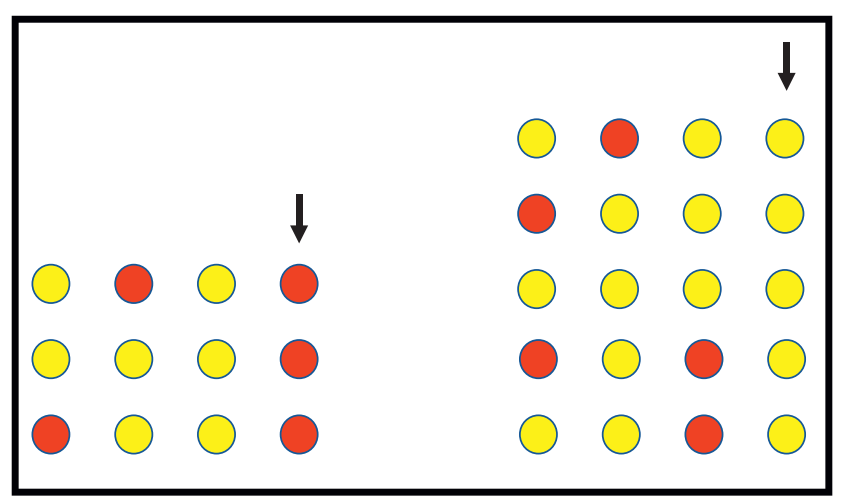

Figure 1: Pictorial representation of Fibonacci recursion [42].

terms, $\left(F_{n+1} / F_{n}\right)$. To this end, one can use a spreadsheet to demonstrate that the ratios $\left(F_{n+1} / F_{n}\right)$ approach the number 1.61803 as $n$ increases, regardless of the first two terms of the sequence, $F_{0}$ and $F_{1}$. The exact value of $\lim _{n \longrightarrow \infty}\left(F_{n+1} / F_{n}\right)=(1+\sqrt{5}) / 2$, the number known as the golden ratio. This is an example of how the use of a computer can provide students and their teachers alike with an informal bridge connecting a lower cognitive level with a higher one. Without the ease of calculating the ratios of two consecutive Fibonacci numbers provided by a spreadsheet, it would be much more difficult to connect a simple action learning activity of a specific arrangement of two-sided counters to a cognitively more complex idea of the convergence of the ratios to a number known from antiquity as the golden ratio. Motivated by a computer, the golden ratio can be discovered in the context of exploring a special number sequence describing an action learning problem appropriate for young children. In other words, a computer can naturally open a window to students' future action learning (see a note about Alzheimer's research in Section 6 below).

In connection with the use of two-sided counters in the context of Fibonacci numbers, it should be noted that many teacher candidates believe that concrete materials can only be utilized at the elementary level and beyond that level, they are of no use. With this in mind, the authors would like to argue that, just as with Fibonacci numbers, concrete materials can be used to introduce rather sophisticated concepts in order to add the factor of concreteness to the study of abstract ideas. In particular, two-sided counters can serve as an embodiment of binary arithmetic in an introductory computer science course. More specifically, if one writes down the first 16 natural numbers in the binary form, then, with the support of two-sided counters, one can see the following. There are two one-digit numbers with no 1's appearing in a row (no red counters back to back), three twodigit numbers with no 1's appearing in a row, five three-digit numbers with no 1's appearing in a row, and eight four-digit numbers with no 1's appearing in a row. The numbers 2, 3, 5, and 8 are consecutive Fibonacci numbers which, thereby, can be used as bits of students' previous knowledge in developing new ideas through action learning. For more secondary (and tertiary)-level explorations with Fibonacci numbers, see [43].
Evidently, motivation becomes connected to an anticipated future success as a consequence of adolescence. Students now seek greater concretization of concepts. When students at the secondary level have strong motivation for action learning, they can, and do, produce undergraduatequality projects, as described for undergraduates in Section 4.2 below. There is a gradual sense of "seriousness" that accompanies "mature" project work. The fine examples of action learning of secondary-level students performing on a college level are seen with Lauren Woodbridge's Publix delivery project "Pallet Physics" ([44], v. 3, 2(8)), Bo Moon's quantum computation project "The Subset Sum Problem: Reducing Time Complexity of NP-Completeness with Quantum Search" ([44], v. 4, 2(2)), Logan White's rocket project "Modeling Rocket Flight in the Low-Friction Approximation" ([44], v. 6, 1(5)), and Roshan Warman's spinbased computing project "Spintronic Circuits: The Building Blocks of Spin-based Computation” ([44], v. 7, 1(1)).

4.1.2. Creativity and Action Learning. Humans are creative when they are motivated, and one may be more creative following general, formative concretizations of ideas. It is important to recognize student creativity early. Educators see creativity as "one of the essential 21st century skills ... vital to individual and organizational success" ([45], p. 1). Teachers' ability to recognize creativity of their students that may be hidden behind their immature classroom performance is critical for successful teaching and productive learning. If students' hidden creativity is not acknowledged and supported by a teacher, it would most likely remain dormant if not vanish [46]. The following story, drawn from a second-grade classroom, supports the notion that teachers are the major custodians of unfolding the creative potential of young children.

An elementary teacher candidate, working individually with a second-grade student (under the supervision of the classroom teacher), asked him to construct all possible rectangles out of ten square tiles (a real problem for grade two), expecting the student to construct two rectangles, 1 by 10 and 2 by 5 , each of which representing a multiplication fact for the number 10, something that would be studied later (in grade three). The teacher candidate was surprised to see three rectangles as shown in Figure 2. A large number of teaching ideas for action learning can stem from the acceptance of the rectangle with a hole which manifests the child's hidden creativity. Some ideas can be connected with secondary mathematics. To clarify, consider exploring the relationship between area and perimeter of this rectangle with a hole, counting both external and internal perimeters (a teacher-guided reflection on taking action by a student using concrete materials). One can see that the area is 10 square units and the perimeter is 20 linear units. That is, numerically, perimeter is twice the area. Comparing areas with perimeters of rectangles has been known from the time of Pythagoras [47]. In the action learning fashion, a situation to be explored can be as follows: Are there other rectangles with rectangular holes for which the perimeter is twice the area? To this end, at the secondary level, one can introduce 


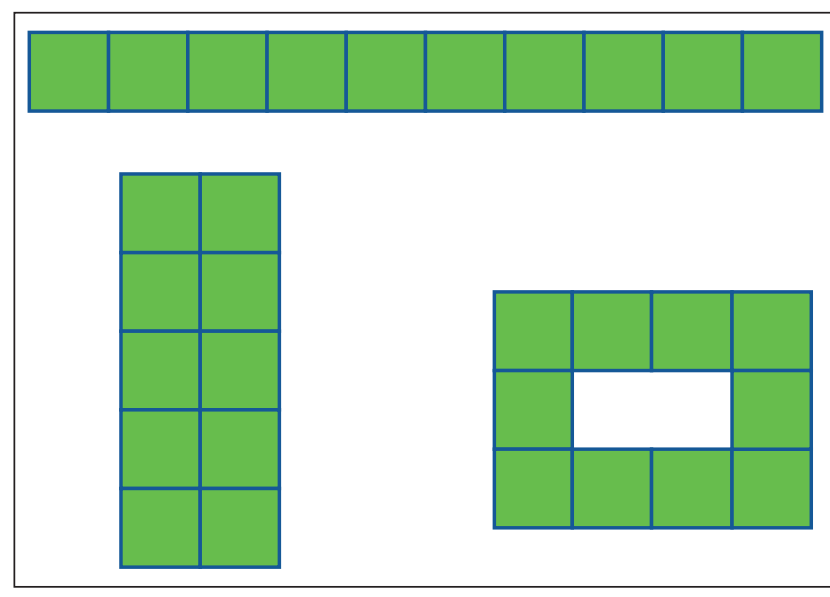

Figure 2: Eight tiles-two rectangles with no windows.

four variables, $a, b, c$, and $d$, as lengths and widths of the larger and smaller rectangles. From here, the relation $a b-c d=a+b+c+d$ follows. Using Wolfram Alpha-a computational knowledge engine available free online-one can ask the program to solve the above equation over the positive integers. The following result would follow:

$$
\begin{aligned}
& a \geq 2, \\
& b>\frac{a}{a-1}, \\
& 0<c<a b-a-b, \\
& d=-\frac{-a b+a+b+c}{c+1} .
\end{aligned}
$$

Setting $a=b=3$, one can choose $c=1$ whence $d=1$. This gives us a square with a square hole (Figure 3 ). This example shows how knowing algebra and affordances of technology can inform practicing teachers' work with young children in promoting critical thinking and fostering creativity. That is, once again, technology serves as an informal bridge motivating connection between two different grade levels of mathematics curriculum. Whereas a teacher may not necessarily see a rich learning milieu behind a nontraditional response by a student, the very fact that such a response has been accepted and praised would motivate this and other students to continue being "out of the box" thinkers.

To conclude this section, note that the troika, an elementary student, a classroom teacher, and a teacher candidate, can be compared in the context of action learning with that of an undergraduate student, a mathematics faculty, and a subject area advisor as described below in Section 4.2.2. The similarity of the two milieus (years apart) is in double supervision of a student action learning of mathematics by a duo of "more knowledgeable others."

\subsection{Undergraduate Mathematics and Action Learning}

4.2.1. Comprehending Abstractness with Learning by Doing. Mathematics language is abstract with greater abstraction at higher levels. Traditionally, university mathematics for

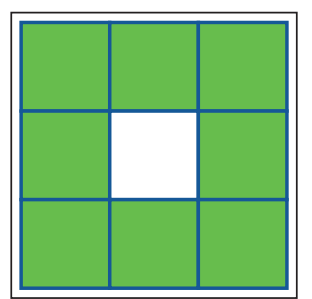

Figure 3: A rectangle (square) with a square window [29].

nonmathematics majors is taught by distancing it from reality with no connection to students' professional interests. In this setting, quite a number of soon-to-be professionals do not see the importance of mathematics in their prospective fields [48]. Furthermore, abstractness in teaching often results in the problem of communication. As noted in [49], in connection with teaching engineering mathematics, there may be discordance between terminology and ideas used by a lecturer mathematician and their interpretation by the students. As a result of being too theoretical, mathematics education at the university level becomes ineffective: nonmathematics majors study the subject matter "because they have to." An alternative approach to mathematics education is based on the well-known and pragmatic notion of "learning by doing" (e.g., [50-54]) which makes it possible a meaningful interplay of pure and applied ideas. This approach has great potential to bring experiential learning to calculus-a basic course sequence in the tertiary mathematics curriculum.

4.2.2. Mathematics Umbrella Model. The entire collegiate mathematics curriculum for nonmathematics majors can benefit from action learning. It is found that, particularly at the collegiate level, there should be a "middle-of-the-road" stance on the relative weights given to theory and application. The Mathematics Umbrella Group (MUG) at the University of South Florida (USF), initiated by Arcadii Grinshpan in 1999 [55], takes this “stance." It bridges the gap between mathematics education and applications, while inspiring STEM students to attain the mathematics skills essential for success in their respective disciplines. This initiative led to the development of the Mathematics Umbrella model in STEM education involving hundreds of interdisciplinary (mathematics application) student projects. In the ten years since reporting that the MUG program was the first organization to facilitate personalized mathematics projects, dually advised by both mathematics and subject area advisors, for teaching nonmathematics majoring STEM students [56], MUG has remained unique in this distinction. Each project is completed under double supervision: a mathematics advisor (mathematics faculty) and a subject area advisor (university or community professional) who usually suggests a problem [4, 48, 55, 57-59].

The hallmark of MUG is its stratagem of interconnecting one undergraduate student with at least two professionals. The situation is illustrated in Figure 4. As a result, students are exposed to a wider range of expertise than is normally privy to the mathematics instructor alone. 


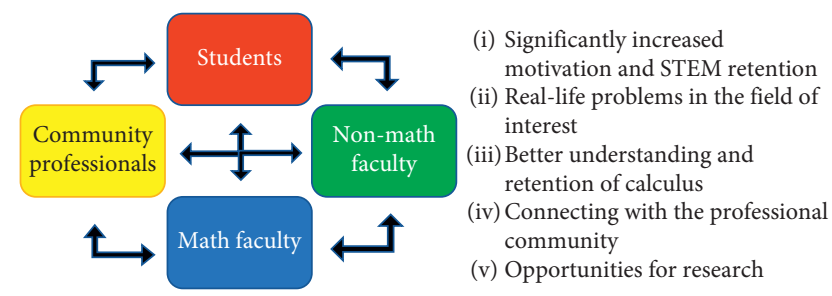

FIGURE 4: Applied mathematics projects connect students with academic and industrial STEM professionals $[4,57]$.

Another strong feature is the community ties which are possible or the interdisciplinary connection that at least takes place beyond the institution's mathematics faculty. Action learning brings "reality" to the abstractions of mathematics. Even when mathematics instructors try to supply problems with applications, the usefulness is not known firsthand until the students put it to use. This is a motivational approach for all parties in the trio. Students may later elect to conduct research in connection with their project experiences. Also, they are likely to retain the concepts involved longer than they might have in the "pure lecture" approach.

4.2.3. Action Learning in Upper-Level Calculus Courses. Action learning is a strong motivating factor for all participants involved in the Mathematics Umbrella Group. This factor seems to be a common thread throughout the K-20 action learning spectrum. The participants' interest in action learning may be proportional to individual experience. Mathematics instructors may potentially get the biggest benefit, but students are expected to know enough of the theory to be motivated as well. For the undergraduate mathematics courses such as calculus II and III, it is deemed sufficient for students to prevail on several smaller tests and homework assignments and then to devote their energies toward action learning, rather than requiring them to succeed on the final examination. In particular, this action learning pedagogy helps students who are "marginally successful" by allowing their final grades to include an action learning component which is justifiably given significant weight in the overall grading for the course.

More often, there are "standard achievers" who may be very productive with their action learning projects. There is the potential for students' work to be published, or perhaps even honored [4,57], as many students have been over the past two decades. These are fine motivators for all parties involved in an action learning endeavor. Since action stems from motivation, it is important to recognize the role of "action motivators." For the tertiary students, a powerful motivator is often in learning something useful and something on which to build or enhance a successful career.

Notably, students are naturally motivated by success in their mathematics courses. The influence of action learning has been analyzed at the University of South Florida in courses of engineering calculus involving thousands of students enrolled in these courses and follow-up courses from Spring 2003 to Spring 2015 [59]. Some results (grouped by race and ethnicity) are given in Figure 5 [59]. This figure shows the effect of action learning, concurrent nonaction learning sections, and historical (traditional) sections. This portion of the investigation involved 1589 action learning students and 1405 students from courses not using the action learning element. Finally, 2316 others were labeled "historical," meaning that they had taken the course before Spring 2003 (i.e., before such a distinction was made as to using or not using action learning in their courses). The researchers were careful to include confidence intervals for their results. It is apparent that in this relatively large subgroup from the larger study, all four of the race/ethnicity categories favor being the action learning participants. There is a lot of information from [59] for consideration. At any rate, this and other results demonstrate the academic superiority in action over nonaction learning. The pragmatic conclusion is to provide action learning, since it works.

\subsubsection{Action Learning as a Universal Educational Concept.} Motivation for mathematics instructors derives from exposure to new experiences with action learning. There are now many hundreds of action learning projects on record, representing a wide range of topics. Additionally, there is always some fine action learning going on, which is never documented. Of those projects which are available in the Undergraduate Journal of Mathematical Modeling: One + Two (UJMM) [44], it is evident that virtually all fields can employ action learning. There are projects dealing with very specific branches of engineering, such as biomedical nanotechnology. There are also many other projects outside of "engineering proper," like those featuring music or even education. Others are cross-field types which defy clear categorization. The bridge types are quite often of special interest. It motivates educators to see what comes up in the mix and which fields may be connected through action learning. These are the interdisciplinary features desired in all of curricula (in the "curriculum universe" that is education). Some details are available from the main Mathematics Umbrella Group website (see Center for Industrial and Interdisciplinary Mathematics). The journal displays a select subgroup of more than 2400 student projects submitted since 2000. An indication of the diverse nature of project topics and student contributors is evident from the variety of subject matters seen in the latest UJMM titles ([44], v. 8, 1-2): “Application of Simple Harmonics Modeling a Shock" by Kai Raymond, "The Forces Affecting a Sailboat" by Kelly Stukbauer, "Optimization of a Fuel Cell" by Eduardo Gines, "Analysis of Rainfall in Tampa" by Amy Polen, "Approximating Surface Area of Fluctuating Lipid Leaflets Using Weighted Grid Tessellation" by Ahnaf Siddiqui, "Rudimentary Model of Glucose Response to Stress" by Nasha Rios-Guzman, "Organic Agricultural Analysis: Efficiency of Common Practices" by Bradley Biega, "Using the Entropy Rate Balance to Determine the Heat Transfer and Work in an Internally Reversible, Polytrophic, Steady State Flow Process" by Savannah Griffin, "Model Function of Women's 1500 m World Record Improvement over Time" by Annie Allmark, "Polycrystalline Silicon Solar Module 


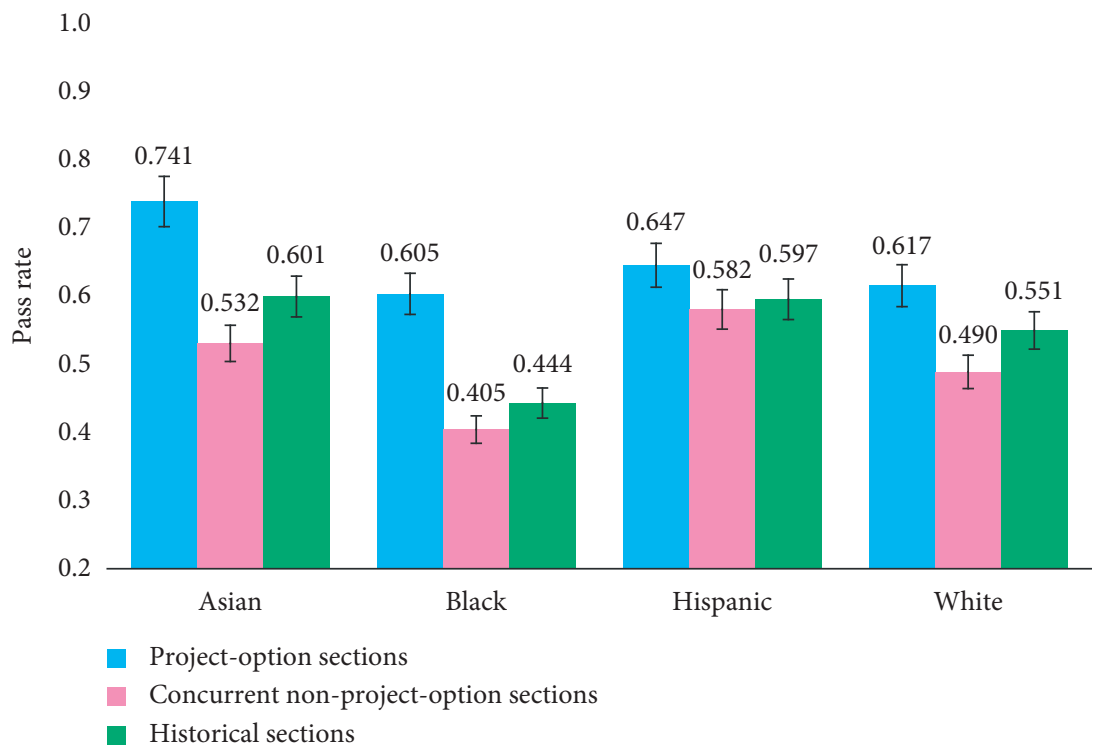

Figure 5: Mean pass rates and 95\% confidence intervals for Engineering Calculus II by race/ethnicity [59].

Power Max" by Jaynil Patel, "Optimization of a Water Gas Shift Reaction" by Ali Albuloushi, and “Tsunami Waves” by Samantha Pennino.

In addition to the many published undergraduate projects, there are "action learning scenarios," which might be viewed as amalgams of different action learning experiences. Several idealistic problems have this mixed experience derivation. The problems might be considered typical of what might be considered in a project, rather than being actual examples. These scenarios provide mathematics instructor motivation to include action learning with the usual largely theoretical course content. The experiences would likely be shared by any mathematics instructors having similar positions in mathematics education. The immediate motivation here is to expand our understanding of the relationship between mathematics theory and solving actual problems in the real world.

\section{Motivating Questions as the Major Means of Learning Mathematics}

5.1. Questions as Instruments of Action Learning. Questions posed generally become more sophisticated as students mature. Instructors at all levels of mathematics education use knowledge and experience to answer questions. Concrete and confident responses are desired, with the occasional possibility (generally at higher levels) that questions may require additional reflection prior to their exposition. In the context of problem-posing and problem-solving, it is important that one distinguishes between two types of questions that can be formulated to become a problem: questions seeking information and questions requesting explanation of the information obtained [60]. Similar to two types of signs - the first-order symbols and the second-order symbolism [61] —one can refer to questions seeking information as the first-order questions and those requesting explanation as the second-order questions [46]. Whereas the first-order questions can be answered using different methods, it appears that not all methods can be used to provide an explanation of what was obtained in search for information, that is, to provide an answer to a second-order question. Often, the request for explanation is an intelligent reflection on a method that provided information.

What does it mean that teachers need to possess "deep understanding" of mathematics? Why do they need to have such understanding? There are several reasons for prospective teachers to be thoroughly mathematically prepared in order to have positive effects on the progress of young learners of mathematics. First, in the modern mathematics classroom, students of all ages are expected and even encouraged to ask questions. In the United States, the national standards already for grades pre-K-2 suggest, "Students' natural inclination to ask questions must be nurtured... [even] when the answers are not immediately obvious" ([19], p. 109). Support to this suggestion can be found in the following comment by an elementary teacher candidate: "It is okay not knowing the answer to the question but it is not okay with leaving that question unanswered." The candidate describes herself as "the type of educator that will always encourage my students to ask themselves some of those same questions that will allow them to participate in some profound thinking."

5.2. International Character of Learning through Asking Questions. Just across the border with the United States, the Ontario Ministry of Education in Canada, through their mathematics curriculum for early grades, sets expectations for teachers to be able to "ask students open-ended questions. . . encourage students to ask themselves similar kinds of questions... [and] model ways in which various kinds of questions can be answered" ([62], p. 17). In order to develop such proficiency, "teachers should know ways to use mathematical drawings, diagrams, manipulative materials, 
and other tools to illuminate, discuss, and explain mathematical ideas and procedures" ([63], p. 33). In Chile, mathematics teachers are expected to "use representations, call on prior knowledge, put forward good questions, and stimulate an inquisitive attitude and reasoning among students" ([64], p. 37). In Australia, mathematics teachers know how to motivate "curiosity, challenge students' thinking, negotiate mathematical meaning and model mathematical thinking and reasoning" ([65], p. 4). The repertoire of learning opportunities the teachers offer to their students includes continuous search for alternative approaches to solving problems as well as helping students to better learn a specific problem-solving strategy with which they have been struggling. National mathematics curriculum in England uses such terms as "practice with increasingly complex problems over time ... [and] can solve problems ... with increasing sophistication" ([66], p. 1). Towards this end, teachers have to be prepared to deal with situations when natural quest for inquiry leads students towards this sophistication and increase in complexity of mathematical ideas. The need for this kind of teacher preparation is confirmed by a teacher candidate who put it as follows: "If a student asks why, and a teacher cannot explain how something has come to be, the student loses all faith and interest in the subject and respect for the teacher."

At the undergraduate level, second-order questions are often discussed. Mathematics instructors are aware that such questions can be valuable for stimulating further inquiries. It may be true that mathematics encountered at the primary and early secondary levels should be unimpeachably understood by mathematics instructors and that students can be "sure" of what is taught. When we begin dealing with, say set theory or two/three-dimensional geometry, there can be enigmatic results which truly stimulate learners to consider studying higher mathematics. The curiosities of mathematics are the things which learners are likely to find attractive. Certainly, it is good for the mathematics instructor to have deep understanding of the topic; however, there may be details to an answer which defy immediate conjuring. In a few rare cases, an answer is not even available. It is expected that students' maturity will allow them to accept that at the higher mathematics levels they are not to lose faith and respect for the instructor, if an explanation is deferred. At earlier stages in mathematics education, learners believe that mathematics is perfect. However, mathematics is just as imperfect as anything else devised by human beings. Students should know this.

\section{Computer-Assisted Signature Pedagogy and the 3P Model of Learning and Teaching}

Curiosity and motivation can also be supported by the use of digital tools as instruments of action learning. As it was shown through examples from precollege mathematics education, computers can facilitate a transition from one cognitive level to another (higher) one. This is consistent with the modern-day use of computers in mathematics research when new results stem from computational experiments. For example, the joy of transition from visual to symbolic when two-sided counters were suggested as means of recursively developing Fibonacci numbers, which could then be modelled within a spreadsheet where, perhaps by serendipity, a definitive pattern in the behavior of the ratios of two consecutive terms could be discovered. This discovery motivates the formal explanation of why the ratios behave in a certain way. Likewise, the transition from numeric description of rectangles in terms of perimeter and area leads to their formal representation. While a rectangle with a hole was discovered by thinking "out of the box," the availability of a digital tool facilitates the transition from visual to symbolic with the subsequent use of the latter representation in a mathematical modeling situation.

The power of computational modeling can serve as a motivation for developing and then exploring more complicated recurrence relations than that of Fibonacci numbers. As discussed in [58], the use of spreadsheet modeling can be applied in the context of Alzheimer's research to study transgenic mice population focusing on a financial feasibility of purchasing two parent mice (male and female) and raising a population of mice of a specified size. An effective approach to this problem involves the theory of recurrence relations that originally were introduced at the secondary level through Fibonacci numbers. The results obtained through spreadsheet modeling can then be used to verify theoretical results. For more details on this project, see [55].

All this leads to the notion of computer-assisted signature pedagogy (CASP) when encouraging reflection and supporting analysis of the action taken by a student in the context of action learning provides CASP with the deep (rather than surface) structure of teaching [67] employed by a teacher as a "more knowledgeable other." Similarly, in an earlier publication, Biggs [15] distinguished between the surface and the deep structures of student approaches to learning by describing the former approach in terms of a student "investing minimal time and effort consistent with appearing to meet requirements ... [whereas the latter approach is] based on interest in subject matter of the task; the strategy to maximize understanding" (p. 6). By adapting Dunkin and Biddle's [68] the presage-context-processproduct model of classroom teaching, Biggs [15] introduced now famous 3P model of student learning pivoted by student believes about learning in general and their current learning milieu (presage), student approach to learning (process), and student learning outcome (product). An inquiry into how the fist $\mathrm{P}$ of the model affects its second $\mathrm{P}$ and, as a consequence, the third $\mathrm{P}$ was carried out by Lizzio, Wilson, and Simons [69] who came out with seven theoretical propositions. One of those propositions was based on an argument that if university students perceive their professors' teaching of courses as robust, then they are more likely to select the deep approach to learning. The authors found this argument to be true not only for the case of tertiary mathematics content courses but also for mathematics methods courses for prospective school teachers. In the modern-day teaching of mathematics, the appropriate use of technology is an important characteristic of the learning environment. In particular, in the context of 
student approach to learning at the deep structure under the umbrella of CASP, one can amplify the use of a single digital tool like a spreadsheet by other modern technologies such as Wolfram Alpha. To this end, CASP, structured by the deep approaches to teaching and learning, can include the use of the so-called integrated spreadsheets [70] which support mathematics teaching at all educational levels with computational robustness of student learning.

\section{Problems and Conjectures That Inspire and Motivate}

The student of mathematics (at any level of education) is likely to encounter exposure to the "futility" of mathematical perfection. In mathematics, there are easily expressed questions (conjectures) which defy answers (proof). It seems to be analogous to the Heisenberg uncertainty principle where there are "limits to precision" in finding both position and momentum, for example. The important notion is that there are not always "standard" solutions to mathematical problems. Knowing this, students can possibly develop further mathematics to resolve some problems. There is a "nonstandard" action learning at work in these cases. The initial pondering is largely theoretical, but eventually an application will be summoned. Notice that the problem need not even be solved, much is bound to be learned in the attempt. This process is motivational. Also, the reflection brings concreteness to the concepts within the problem and relates to the overall "nature" of problems and problemsolving.

Real-life applications of mathematics provide a great deal of stimulation for various kinds of research in the subject matter field, involving professional mathematicians and students of different majors alike. This is not to say that applied mathematics is the only meaningful source of the development of mathematical thought. Indeed, there are many problems within mathematics itself that used to motivate and keep motivating those who seek to gain full appreciation of mathematics as a fundamental science. Some of these problems (sometimes referred to as conjectures) can be recommended to be a part of mathematics curriculum for nonmathematics majors as well as for teacher candidates. The authors' experience indicates that theorems and conjectures with origins in both pure and applied mathematics have the potential to trigger imagination and thought process of those whose mind is open to challenge.

For example, the statements and historical details of such exciting problems as Fermat's Last Theorem proved by Andrew Wiles [71] and Bieberbach's conjecture proved by De Branges [72] (see also [73]) may be included into some basic mathematics courses for nonmathematics majors. Proofs of these theorems not only require more than elementary means but also are enormously complex. However, as Stewart [74] noted, "the fact that proof is important for the professional mathematician does not imply that the teaching of mathematics to a given audience must be limited to ideas whose proofs are accessible to that audience" (p. 187). Let us take a look at them.
Fermat's Last Theorem states that equation $x^{n}+y^{n}=z^{n}$ has no nonzero integer solutions for $x, y$, and $z$ when $n>2$. In particular, this theorem can be introduced to different populations of mathematics students as a way of answering the question: Is it possible to extend the interpretation of Pythagorean triples as partitioning a square into the sum of two squares to include similar representations for higher powers? As detailed elsewhere [75], the use of a spreadsheet with secondary teacher candidates enables a way of visualizing Fermat's Last Theorem by modeling nonexisting solutions to the above equation for $n>2$ in much the same way as for $n=2$. Likewise, it is quite possible that with the help of technology or through other means, a natural bridge between the statement of Fermat's Last Theorem and some geometric properties of modular elliptic curves in Wiles's proof will be accessible to future mathematics students.

The Bieberbach conjecture states that for each $n=2,3, \ldots$ and each analytic function $f(z)=z+a_{2} z^{2}+a_{3} z^{3}+\ldots$ that is one-to-one in the unit disk $D=\{z:|z|<1\}$, the inequality $\left|a_{n}\right| \leq n$ holds. This legendary result with its stunning record alone (see, e.g., [76]) can inspire students' interest in learning such important mathematical concepts as one-toone functions, power series, convergence, and Taylor coefficients which, in particular, are appropriate to be discussed with engineering majors. The deep geometric roots of the Bieberbach conjecture are worth mentioning here as well. For example, its proof for $n=2$ is based on presenting a plane set area as a contour integral and thus it is accessible to nonmathematics majors enrolled in an upper-level calculus course.

There is also famous Goldbach's conjecture [77] which asserts that every even number greater than two can be written as the sum of two prime numbers (perhaps, in more than one way). It would be miraculous, if the conjecture was found to be false. So far, no counter example has been found. While searching for a counter example seems fruitless, it has been shown empirically that Goldbach's conjecture is true for all even numbers greater than two and less than some known number having 17 digits.

Another famous yet easy to understand problem is the Palindrome conjecture [78]. It deals with the property of palindromes (i.e., integers that read the same backward as forward) to attract whole numbers under the following procedure: start with any whole number, reverse its digits, and add the two numbers; repeat the process with the sum and continue to see that it leads to a palindrome. Remarkably, this "number game" has been mentioned recently as one of the twelve unsolved problems in contemporary mathematics [79]. It is this problem and as noted in the Principles and Standards for School Mathematics [19], its educational potential for middle school students to "appreciate the true beauty of mathematics" (p. 21), that motivated a secondary teacher candidate to work with one of the authors on developing computational learning environments for instructional presentation of and experimentation with a large class of recreational problems both solved and unsolved [80]. As Gauss put it, "In arithmetic the most elegant theorems frequently arise experimentally as the result of a more or less unexpected stroke of good fortune, 
while their proofs lie so deeply embedded in darkness that they defeat the sharpest inquiries" (cited in [81], p. 112).

It appears that using technology for meaningful experimentation with numbers under the umbrella of CASP has the potential to inspire and motivate students already at the precollege level towards new discoveries in elementary number theory. By expanding our understanding of mathematics in any way, we potentially expand our ability to "flourish." This is the inherent value and motivation for action learning. All of mathematics is conjectured to provide applications. We only need be motivated to devise those applications.

\section{Conclusion}

This paper, using the authors' experience in mathematics teaching and supervising applications of the subject matter in the practice of public schools and industry, introduced the framework of the joint use of action learning and concept motivation in the context of K-20 mathematics education. Different examples of the action learning-an individual work on a real problem followed by reflection under the supervision of a "more knowledgeable other"-have been provided. Such supervision may include a "duo of others" - a classroom teacher and a teacher candidate in a K-12 school, and mathematics faculty and subject area advisor at a university. The paper has demonstrated that action learning of mathematics goes hand in hand with concept motivation-a teaching methodology where the introduction of mathematical concepts is motivated by (grade appropriate) real-life applications which may include student action on objects leading to formal description of this action through the symbolism of mathematics. This approach is based on notable recommendations by mathematicians $[5,16,17]$ and educational psychologists $[1,25,26,61]$.

The main concluding message of the paper is that by repeatedly utilizing concept motivation and action learning at all levels of mathematics education, overall student success has great potential to improve. This message is supported by examples of creative thinking of young learners in the classroom grounded in comprehensive collaboration of school teachers and university faculty (in the spirit of the Holmes Group [82]). Likewise, the message was supported by examples of student interest in the study of calculus through action learning in a real-life setting. It appears that the emerging student interest in mathematics is due to action learning and concept motivation having been used to rectify the widespread formalism in mathematics teaching which, in particular, has become an obstacle to the success of STEM education $[4,7,8]$. When students have experience with action learning of mathematics during their school years, they are likely to continue learning the subject matter in the same vein, thereby avoiding many bumps of the secondary-tertiary transition. As mentioned in Section 4.2.3, research on implementing action learning of engineering calculus, involving thousands of students at the University of South Florida [4,59], indicates that while students' interest in action learning may be proportional to an individual experience of that kind, their learning outcomes demonstrate academic superiority of action learning over other pedagogical means of calculus delivery.

At the onset of formal mathematics education, schoolchildren should begin experiencing action learning and concept motivation pedagogy enhanced, as appropriate, by asking and answering questions and learning to use technology. As was shown in the paper, not only K-12 mathematics curricula of many countries support student learning through asking questions but also their future teachers appreciate that kind of mathematical learning. Likewise, computer-assisted signature pedagogy [37] can be used to maximize student understanding of mathematics and to encourage their deep approach to learning [15]. University undergrads have greater motivation than schoolchildren in order to handle the responsibilities of adulthood. Yet, both populations of students can still be motivated by their natural "age-defying" curiosity. In this regard, stimulating questions, the affinity for using computers, and classical famous problems are important motivating tools in the study of mathematics. Subsuming the entire K-20 mathematics curriculum under a single umbrella is practicable when techniques of concept motivation and action learning are in place throughout that educational spectrum. Finally, there is clearly a pragmatic reason for exposing students to the action learning rainbow, and that is because among today's students are tomorrow's teachers. The process should continue to flourish.

\section{Data Availability}

The data used to support the findings of this study are included within the article.

\section{Conflicts of Interest}

The authors declare that they have no conflicts of interest.

\section{References}

[1] J. Dewey, Democracy and Education, Free Press, New York, NY, USA, 1916.

[2] S. Billett, "Realising the educational worth of integrating work experiences in higher education," Studies in Higher Education, vol. 34, no. 7, pp. 827-843, 2009.

[3] S. Billett, "Learning in the circumstances of practice," International Journal of Lifelong Education, vol. 34, no. 7, pp. 827-843, 2014.

[4] S. Abramovich, J. Burns, S. Campbell, and A. Z. Grinshpan, "STEM education: action learning in primary, secondary, and post-secondary mathematics," IMVI Open Mathematical Education Notes, vol. 6, pp. 65-106, 2016.

[5] H. Bass, "Mathematicians as educators," Notices of the American Mathematical Society, vol. 44, no. 1, pp. 18-21, 1997.

[6] J. Baumert, M. Kunter, W. Blum et al., "Teachers' mathematical knowledge, cognitive activation in the classroom, and student progress," American Educational Research Journal, vol. 47, no. 1, pp. 133-180, 2010.

[7] Executive Office of the President, Engage to Excel: Producing One Million Additional College Graduates with Degrees in Science, Technology, Engineering, and Mathematics, President's 
Council of Advisors on Science and Technology, Washington, DC, USA, 2012.

[8] E. M. Friedlander, T. S. Holm, J. Ewing et al., "Mathematicians' central role in educating the STEM workforce," 2012, http://www.ams.org/policy/govnews/pcast-statement.

[9] D. Guin and L. Trouche, "The complex process of converting tools into mathematical instruments: the case of calculators," International Journal of Computers for Mathematical Learning, vol. 3, no. 3, pp. 195-227, 1999.

[10] P. W. Thompson, M. Artigue, G. Töner, and E. de Shalit, "Collaboration between mathematics and mathematics education," in Mathematics and Mathematics Education: Searching for the Common Ground, M. Fried and T. Dreyfus, Eds., pp. 313-333, 2014.

[11] N. Livson, "Towards a differentiated construct of curiosity," The Journal of Genetic Psychology, vol. 111, no. 1, pp. 73-84, 1967.

[12] D. C. Vidler, "Curiosity," in Motivation in Education, S. Ball, Ed., pp. 17-43, Academic Press, New York, NY, USA, 1977.

[13] G. Pólya, Induction and Analogy in Mathematics, Vol. 1, Princeton University Press, Princeton, NJ, USA, 1954.

[14] D. C. Vidler, "Achievement motivation," in Motivation in Education, S. Ball, Ed., pp. 67-89, Academic Press, New York, NY, USA, 1977.

[15] J. Biggs, "What do inventories of students' learning processes really measure? A theoretical review and clarification," British Journal of Educational Psychology, vol. 63, no. 1, pp. 3-19, 1993.

[16] B. B. Mandelbrot, "Fractals, the computer, and mathematics education" in Proceedings of the 7th International Congress on Mathematical Education (Plenary lectures), C. Gaulin, B. R. Hodson, D. H. Wheeler, and J. C. Egsgard, Eds., pp. 77-98, Les Presses de L'université Laval, Sainte-oy, Québec, Canada, August 1994.

[17] D. Hilbert, "Mathematical problems," Bulletin of the American Mathematical Society, vol. 8, no. 10, pp. 437-480, 1902.

[18] USF, "FKL core curriculum for students," 2018, https://www. usf.edu/undergrad/fkl/.

[19] National Council of Teachers of Mathematics, Principles and Standards for School Mathematics, National Council of Teachers of Mathematics, Washington, DC, USA, 2000.

[20] R. Revans, Action Learning: New Techniques for Management, Blond \& Briggs, London, UK, 1980.

[21] R. Revans, The Origin and Growth of Action Learning, Chartwell-Bratt, Brickley, UK, 1982.

[22] J. Biggs, Teaching for Quality Learning at University: What the Student Does, The Society for Research into Higher Education \& Open University Press, Philadelphia, PA, USA, 2003.

[23] R. Dilworth, "Action learning in a nutshell," Performance Improvement Quarterly, vol. 11, no. 1, pp. 28-43, 1988.

[24] D. Beswick, "Theory and measurement of human curiosity," Unpublished Doctoral Dissertation, Harvard University, Cambridge, MA, USA, 1965.

[25] M. Wertheimer, Productive Thinking, Harper \& Brothers, New York, NY, USA, 1959.

[26] W. James, Talks to Teachers on Psychology, Harvard University Press, Cambridge, MA, USA, 1983.

[27] L. W. Rust, "Interests," in Motivation in Education, S. Ball, Ed., pp. 131-146, Academic Press, New York, NY, USA, 1977.

[28] G. C. Fanelli, "Locus of control," in Motivation in Education, S. Ball, Ed., pp. 45-66, Academic Press, New York, NY, USA, 1977.

[29] J. Elliott, Action Research for Educational Change, Open University Press, Buckingham, UK, 1991.
[30] D. Kember, Action Learning and Action Research: Improving the Quality of Teaching and Learning, Kogan Page, London, UK, 2000.

[31] A. Lizzio and K. Wilson, "Action learning in higher education: an investigation of its potential to develop professional capability," Studies in Higher Education, vol. 29, no. 4, pp. 469-488, 2007.

[32] I. Naftalin, "Action learning in higher education," Educational Management and Administration, vol. 24, no. 2, pp. 193-205, 1996.

[33] D. Greenwood and M. Levin, Introduction to Action Research, Sage Publications, Thousand Oaks, CA, USA, 2nd edition, 2007.

[34] L. Norton, Action Research in Teaching and Learning: A Practical Guide to Conducting Pedagogical Research in Universities, Routledge, New York, NY, USA, 2009.

[35] L. Phillips, Using Action Learning to Support the Development of Primary Teachers' Mathematical Knowledge, The National Teacher Research Panel, Coventry, UK, 2010.

[36] G. J. Pine, Teacher Action Research: Building Knowledge Democracies, SAGE Publications, Thousand Oaks, CA, USA, 2008.

[37] S. Abramovich, J. Easton, and V. O. Hayes, "Parallel structures of computer-assisted signature pedagogy: the case of integrated spreadsheets," Computers in the Schools, vol. 29, no. 1-2, pp. 174-190, 2012.

[38] C. Kyrlacou, "Active learning in secondary school mathematics," British Educational Research Journal, vol. 18, no. 3, pp. 309-318, 1992.

[39] J. S. Rosenthal, "Active learning strategies in advanced mathematics classes," Studies in Higher Education, vol. 20, no. 2, pp. 223-228, 1995.

[40] N. F. Ellerton, "Engaging pre-service middle-school teachereducation students in mathematical problem posing: development of an active learning framework," Educational Studies in Mathematics, vol. 83, no. 1, pp. 87-101, 2013.

[41] M. Kogan and S. L. Laursen, "Assessing long-term effects of inquiry-based learning: a case study from college mathematics," Innovative Higher Education, vol. 39, no. 3, pp. 183-199, 2014.

[42] S. Abramovich and G. A. Leonov, "Fibonacci numbers revisited: technology-motivated inquiry into a twoparametric difference equation," International Journal of Mathematical Education in Science and Technology, vol. 39, no. 6, pp. 749-766, 2008.

[43] S. Abramovich and G. A. Leonov, Revisiting Fibonacci Numbers through a Computational Experiment, Nova Science Publishers, New York, NY, USA, 2019.

[44] The Undergraduate Journal of Mathematical Modeling: One + Two, 2019, http://scholarcommons.usf.edu/ujmm/.

[45] A. Beghetto, J. Kaufman, and J. Baer, Teaching for Creativity in the Common Core Classroom, Columbia University, New York, NY, USA, 2015.

[46] S. Abramovich, Integrating Computers and Problem Posing in Mathematics Teacher Education, World Scientific, Singapore, 2018.

[47] B. L. Van der Waerden, Science Awakening, Oxford University Press, New York, NY, USA, 1961.

[48] S. Abramovich and A. Z. Grinshpan, "Teaching mathematics to non-mathematics majors through applications," Primus, vol. 18, no. 5, pp. 411-428, 2008.

[49] W. Maull and J. Berry, "A questionnaire to elicit the mathematical concept images of engineering students," International Journal of Mathematical Education in Science and Technology, vol. 31, no. 6, pp. 899-917, 2000. 
[50] J. Dewey, How we Think: A Restatement of the Relation of Reflective Thinking to the Educative Process, Heath, Boston, MA, USA, 1933.

[51] L. V. Ahlfors, "On the mathematics curriculum of the high school," American Mathematical Monthly, vol. 69, no. 3, pp. 189-193, 1962.

[52] R. Noss and C. Hoyles, "The visibility of meaning: modeling the mathematics of banking," International Journal of Computers for Mathematical Learning, vol. 1, no. 1, pp. 3-31, 1996.

[53] C. R. Hadlock, Mathematical Modeling in the Environment, The Mathematical Association of America, Washington, DC, USA, 1998.

[54] A. E. Kelly, R. A. Lesh, and J. Y. Baek, Handbook of Design Research Methods in Education: Innovations in Science, Technology, Engineering, and Mathematics Learning and Teaching, Routledge, New York, NY, USA, 2008.

[55] A. Z. Grinshpan, "The Mathematics Umbrella: modeling and education," in Mathematics in Service to the Community: Concepts and Models for Service-Learning in the Mathematical Sciences, C. Hadlock, Ed., MAA Notes \#66, pp. 59-68, Washington, DC, USA, 2005.

[56] D. Milligan, "The effect of optional real world application projects on mathematics achievement among undergraduate students," Graduate Theses and Dissertations, 2007, http:// scholarcommons.usf.edu/etd/2290.

[57] A. Z. Grinshpan, "Interdisciplinary mathematics in STEM education: undergraduate retention and research," in NSF STEP Grantees Meeting: Identifying Best Practices, Washington, DC, USA, 2014, http://stem-central.net/groups/ posts/936/, http://ciim.usf.edu/docs/NSF_STEP_2014_-_ Interdisciplinary_Mathematics_in_STEM_Education.pdf.

[58] S. Abramovich and A. Z. Grinshpan, "Bridging K-12 and university mathematics: building the staircase from the top," IMVI Open Mathematical Education Notes, vol. 2, pp. 1-21, 2012.

[59] G. Fox, S. Campbell, A. Z. Grinshpan et al., "Implementing projects in calculus on a large scale at the university of South Florida," Journal of STEM Education, vol. 18, no. 3, pp. 30-38, 2017.

[60] N. Isaacs, "Children's why questions," in Intellectual Growth in Young Children, S. Isaacs, Ed., pp. 291-349, Routledge \& Kegan Paul, London, England, 1930.

[61] L. S. Vygotsky, Mind in Society, MIT Press, Cambridge, MA, USA, 1978.

[62] Ontario Ministry of Education, "The Ontario curriculum, grades 1-8, mathematics (revised) (on-line materials),” 2005, http://www.edu.gov.on.ca.

[63] Conference Board of the Mathematical Sciences, The Mathematical Education of Teachers II, The Mathematical Association of America, Washington, DC, USA, 2012.

[64] P. Felmer, R. Lewin, S. Martínez et al., Primary Mathematics Standards for Pre-Service Teachers in Chile, World Scientific, Singapore, 2014.

[65] Australian Association of Mathematics Teachers, "Standards for excellence in teaching mathematics in Australian schools (on-line materials)," 2006, https://www.aamt.edu.au.

[66] Department for Education, "National curriculum in England: mathematics programmes of study," Crown Copyright, 2013, https://www.gov.uk/government/publications/ national-curriculum-in-england-mathematics-programmes-ofstudy.

[67] L. S. Shulman, "Signature pedagogies in the professions," Daedalus, vol. 134, no. 3, pp. 52-59, 2005.
[68] M. J. Dunkin and B. J. Biddle, The Study of Teaching, Holt, Rinehart \& Winston, New York, NY, USA, 1974.

[69] A. Lizzio, K. Wilson, and R. Simons, "University students' perceptions of the learning environment and academic outcomes: implications for theory and practice," Studies in Higher Education, vol. 27, no. 1, pp. 27-52, 2002.

[70] S. Abramovich, Exploring Mathematics with Integrated Spreadsheets in Teacher Education, World Scientific, Singapore, 2016.

[71] G. Faltings, "The proof of Fermat's Last theorem by R. Taylor and A. Wiles," Notices of the American Mathematical Society, vol. 42, no. 7, pp. 743-746, 1995.

[72] L. De Branges, "A proof of the Bieberbach conjecture," Acta Mathematica, vol. 154, no. 1-2, pp. 137-152, 1985.

[73] A. Z. Grinshpan, "The Bieberbach conjecture and Milin's functionals," The American Mathematical Monthly, vol. 106, no. 3, pp. 203-214, 1999.

[74] I. Stewart, "Change," in On the Shoulders of Giants: New Approaches to Numeracy, L. A. Steen, Ed., pp. 183-217, The National Academies Press, Washington, DC, USA, 1990.

[75] S. Abramovich, "Revisiting an ancient problem through contemporary discourse," School Science and Mathematics, vol. 99, no. 3, pp. 148-155, 1999.

[76] A. Z. Grinshpan, "Logarithmic geometry, exponentiation, and coefficient bounds in the theory of univalent functions and nonoverlapping domains," in Handbook of Complex Analysis: Geometric Function Theory, R. K'uhnau, Ed., vol. 1, pp. 273-332, North-Holland, Amsterdam, Netherlands, 2002.

[77] E. W. Weisstein, "Goldbach conjecture," in CRC Concise Encyclopedia of Mathematics, p. 742, Chapman \& Hall/CRC, Washington, DC, USA, 1999.

[78] E. W. Weisstein, "Palindromic number conjecture," in CRC Concise Encyclopedia of Mathematics, pp. 1301-1302, Chapman \& Hall/CRC, Washington, DC, USA, 1999.

[79] S. W. Williams, "Million-buck problems," The Mathematical Intelligencer, vol. 24, no. 3, pp. 17-20, 2002.

[80] S. Abramovich and T. Strock, "Measurement model for division as a tool in computing applications," International Journal of Mathematical Education in Science and Technology, vol. 33, no. 2, pp. 171-185, 2002.

[81] D. E. Smith, A Source Book in Mathematics, Vol. 2, Dover, New York, NY, USA, 1959.

[82] Holmes Group, Tomorrow's Schools of Education, Holmes Group, East Lansing, MI, USA, 1995. 


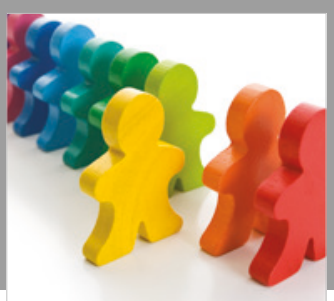

Autism

Research and Treatment
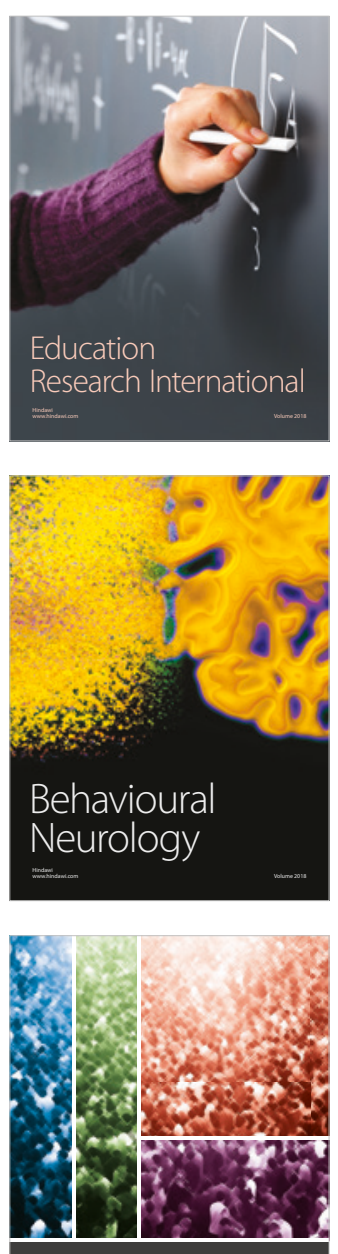

International Journal of

Population Research

$\underline{-m}$

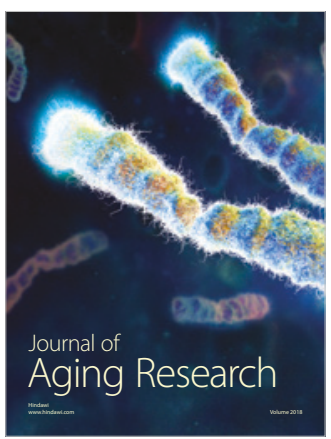

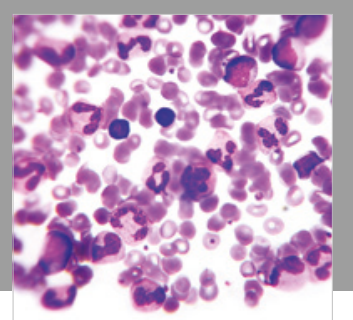

Pathology

Research International$$
=
$$

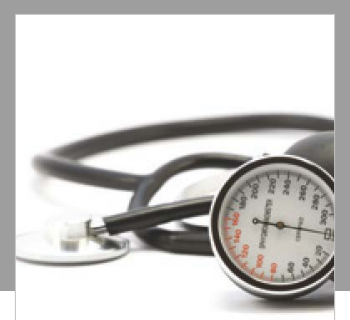

Nursing

Research and Practice

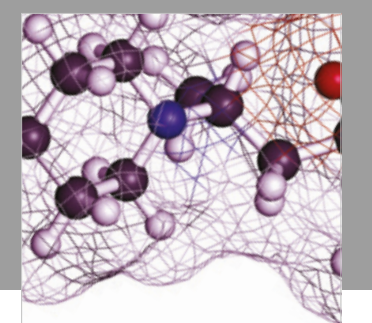

Pain

Research and Management

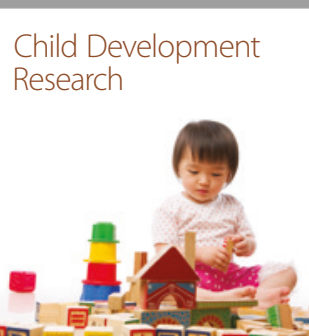

बाD

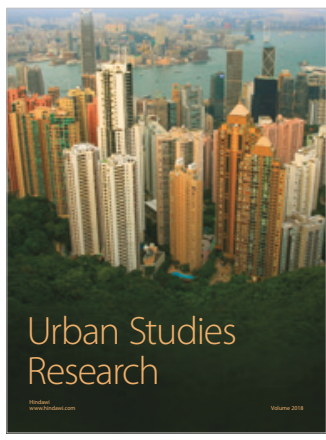

\section{Hindawi}

Submit your manuscripts at

www.hindawi.com
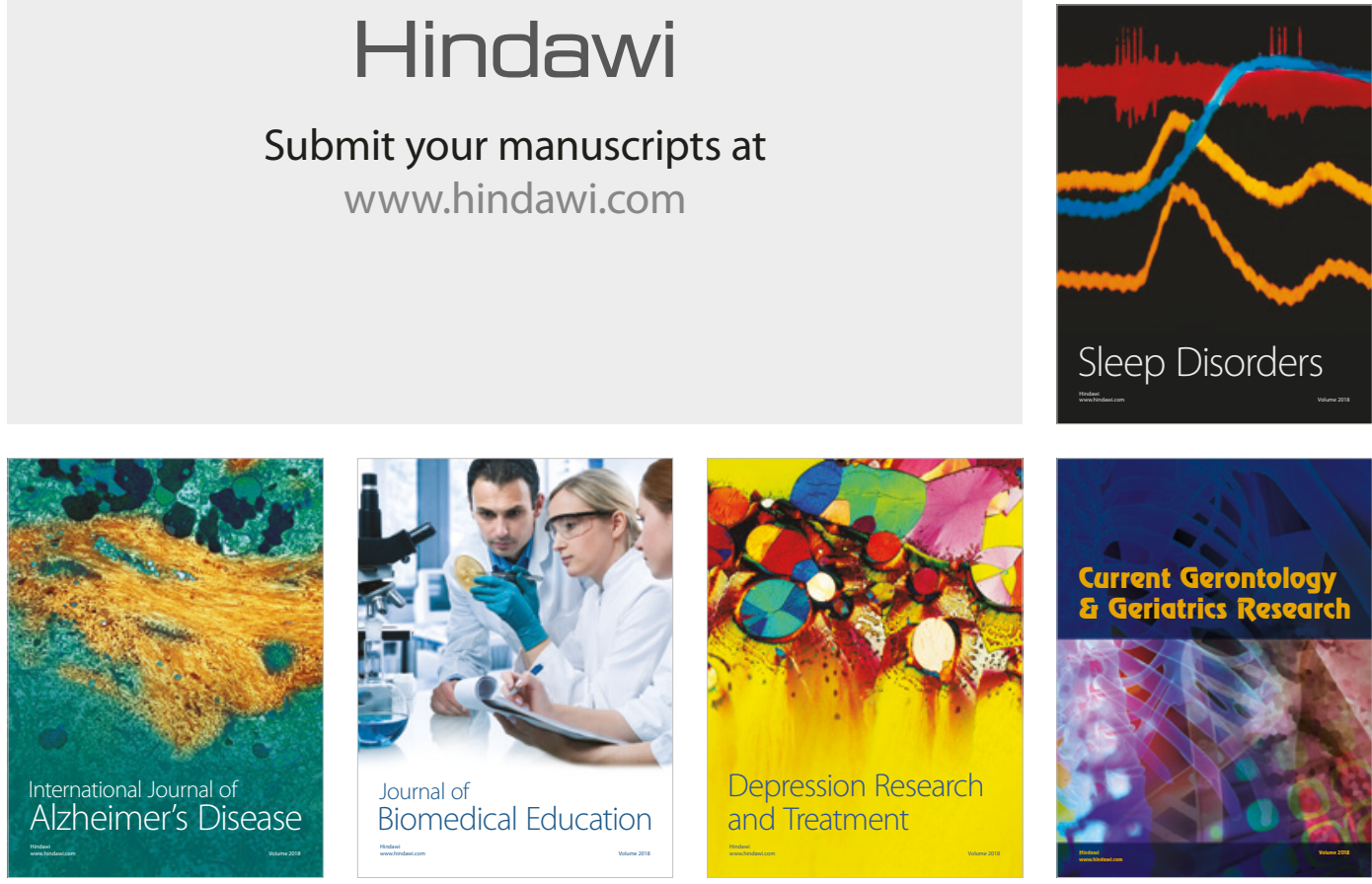

Journal of

Biomedical Education

$=$

smman

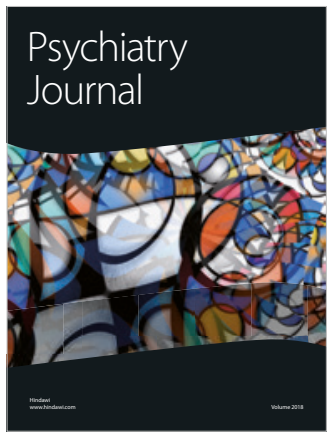

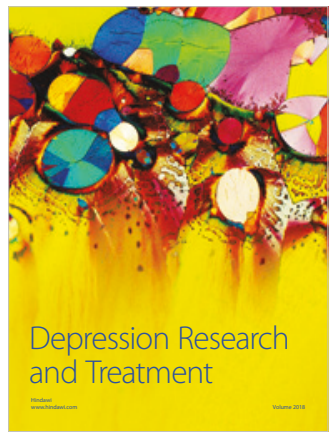
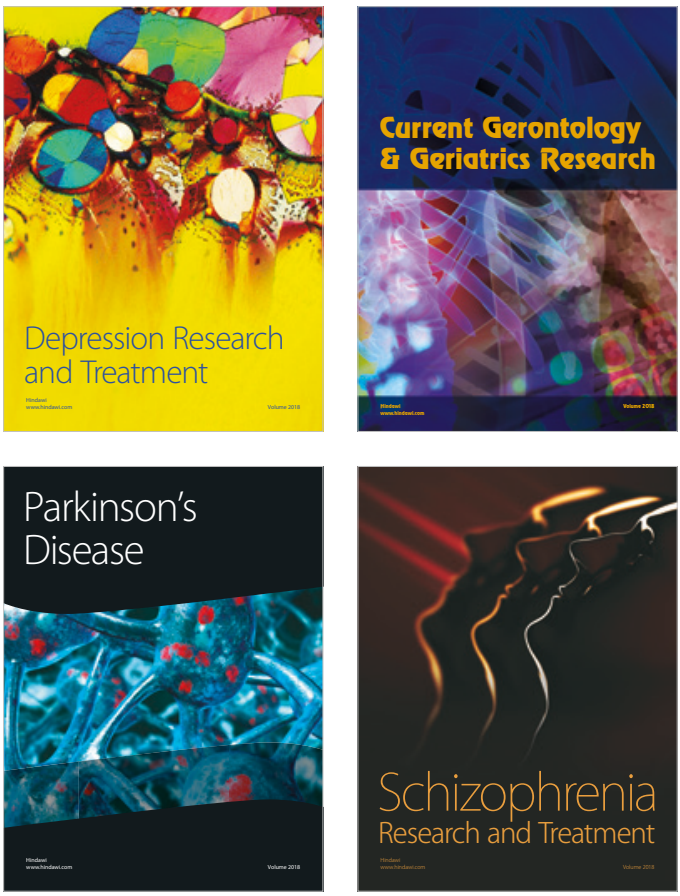